Pharma, Lilly, Medlmmune, Merck, Novartis, Pfizer, Regeneron, Roche, Sanofi Genzyme, Stiefel, Sun Pharma, Takeda, and UCB., Leslie McCasland Speakers bureau: LM has received fees for serving on an advisory board from Lilly., Douglas White Speakers bureau: DW has received honoraria or fees for serving on advisory boards, as a speaker, and as a consultant from AbbVie, Merck, Novartis, and Roche., Consultant of: DW has received honoraria or fees for serving on advisory boards, as a speaker, and as a consultant from AbbVie, Merck, Novartis, and Roche., Lisa Barcomb Shareholder of: LB is a full-time employee of AbbVie, and may hold AbbVie stock or stock options., Employee of: LB is a full-time employee of AbbVie, and may hold AbbVie stock or stock options., Wenjing Lu Shareholder of: WL is a full-time employee of AbbVie, and may hold AbbVie stock or stock options., Employee of: WL is a full-time employee of AbbVie, and may hold AbbVie stock or stock options., Zailong Wang Shareholder of: ZE is a full-time employee of AbbVie, and may hold AbbVie stock or stock options., Employee of: ZE is a full-time employee of AbbVie, and may hold AbbVie stock or stock options., Ahmed M. Soliman Shareholder of: AMS is a full-time employee of AbbVie, and may hold AbbVie stock or stock options., Employee of: AMS is a full-time employee of AbbVie, and may hold AbbVie stock or stock options., Ann Eldred Shareholder of: AE is a full-time employee of AbbVie, and may hold AbbVie stock or stock options., Employee of: AE is a fulltime employee of AbbVie, and may hold AbbVie stock or stock options., Frank Behrens Speakers bureau: FB has received research grants, honoraria, or fees for serving as a consultant or speaker from AbbVie, Amgen, Boehringer Ingelheim, Celgene, Chugai, Galapagos, Genzyme, Gilead, Janssen, Lilly, Merck, Novartis, Pfizer, Roche, and Sanofi., Consultant of: FB has received research grants, honoraria, or fees for serving as a consultant or speaker from AbbVie, Amgen, Boehringer Ingelheim, Celgene, Chugai, Galapagos, Genzyme, Gilead, Janssen, Lilly, Merck, Novartis, Pfizer, Roche, and Sanofi., Grant/research support from: FB has received research grants, honoraria, or fees for serving as a consultant or speaker from AbbVie, Amgen, Boehringer Ingelheim, Celgene, Chugai, Galapagos, Genzyme, Gilead, Janssen, Lilly, Merck, Novartis, Pfizer, Roche, and Sanofi.

DOI: 10.1136/annrheumdis-2021-eular.2678

\section{AB0560 EFFECT OF DEUCRAVACITINIB ON THE PSORIATIC ARTHRITIS IMPACT OF DISEASE (PSAID) QUESTIONNAIRES 12 AND 9: ANALYSIS OF A PHASE 2 STUDY OF ACTIVE PSORIATIC ARTHRITIS}

L. Gossec ${ }^{1}$, L. C. Coates ${ }^{2}$, A. Ogdie ${ }^{3}$, P. J. Mease ${ }^{4}$, T. Lehman ${ }^{5}$, M. Nowak ${ }^{6}$, L. Wei ${ }^{7}$, J. Ye ${ }^{8}$, J. Choi ${ }^{9}$, J. Zhuo ${ }^{9}$, B. Becker ${ }^{9}{ }^{1}$ Sorbonne Université, Pitié Salpêtrière Hospital, Department of Rheumatology, Paris, France; ${ }^{2}$ University of Oxford, Department of Orthopaedics, Rheumatology and Musculoskeletal Sciences, Oxford, United Kingdom; ${ }^{3}$ Perelman School of Medicine, University of Pennsylvania, Division of Rheumatology and Center for Clinical Epidemiology and Biostatistics, Philadelphia, United States of America; ${ }^{4}$ Swedish Medical Center/Providence St. Joseph Health and University of Washington, Rheumatology Research, Seattle, United States of America; ${ }^{5}$ Bristol Myers Squibb, Rheumatology, Princeton, United States of America; ${ }^{6}$ Bristol Myers Squibb, Clinical R\&D, Princeton, United States of America; ${ }^{7}$ Bristol Myers Squibb, Medical Immunology, Princeton, United States of America; ${ }^{8}$ Bristol Myers Squibb, Medical Affairs, Princeton, United States of America; ${ }^{9}$ Bristol Myers Squibb, HEOR, Princeton, United States of America

Background: Tyrosine kinase 2 (TYK2) is an intracellular kinase that mediates IL-23, IL-12, and IFN $\alpha / \beta$ signaling. Deucravacitinib is a novel, oral selective inhibitor of TYK2 via the TYK2 regulatory domain. Phase 2 results showed deucravacitinib was efficacious and well tolerated versus placebo (PBO) in patients (pts) with active psoriatic arthritis (PsA). The Psoriatic Arthritis Impact of Disease (PsAID) questionnaire is a EULAR-developed, validated instrument designed to specifically assess the impact of PsA on health-related quality of life (HRQoL) from the pt's perspective and is available as separate versions for clinical practice (PsAID-12) and clinical trials (PsAID-9). ${ }^{1}$

Objectives: To compare the effect of deucravacitinib vs PBO on PSAID-12 and PsAID-9 responses and to assess relationships between PSAID scores and clinical and pt-reported outcome (PRO) measures.

Methods: This is an ongoing, 1-year, double-blind, Phase 2 trial (NCT03881059). Pts with active PsA were randomized 1:1:1 to deucravacitinib $6 \mathrm{mg}$ or $12 \mathrm{mg}$ once daily, or PBO for 16 weeks (wk). PsAID-12 and PsAID-9, other PROs, and clinical response outcomes were assessed at baseline (BL) and Wk 16. Mean changes from BL in PsAID-12 and PsAID-9 total scores at Wk 16 were determined for each treatment group as well as by response outcomes (ie, achievement of response at Wk 16 for PROs and select clinical response outcomes; Table 1). Spearman correlations between PSAID-12 and PSAID-9 scores and clinical and PRO measures were also assessed.
Results: 203 pts were randomized and BL characteristics were similar across groups. Adjusted mean changes from BL in PsAID-12 and PsAID-9 scores at Wk 16 were significantly greater in the deucravacitinib groups vs PBO (Figure 1). Adjusted mean changes from BL in PsAID-12 and PsAID-9 scores at Wk 16 were significantly improved with deucravacitinib vs $\mathrm{PBO}$ in pts who achieved response for PROs, as well as PASDAS low disease activity and PASI 75 response (Table 1). Adjusted mean changes from BL were generally similar with deucravacitinib vs $\mathrm{PBO}$ in nonresponders. Spearman correlation analysis revealed significant correlations at BL and Wk 16 between PsAID-12 and PsAID-9 scores and clinical and PRO measures $(P<0.0001)$.

Conclusion: With deucravacitinib vs PBO, PsAID-12 and PsAID-9 scores were significantly improved vs BL at WK 16. PsAID detected additional improvements among pts achieving response for multiple other PROs and select clinical outcome measures.

REFERENCES:

[1] Gossec L et al. Ann Rheum Dis. 2014;73:1012-9.

Figure. Adjusted mean change from baseline in PsAID-12 and PsAID-9 total scores at Wk 16

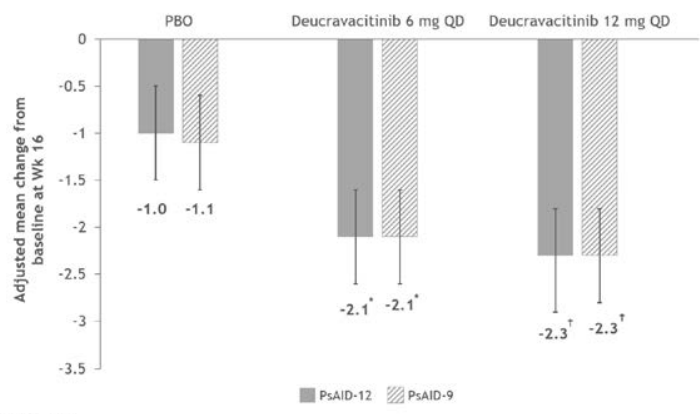

Table 1. Adjusted mean change from BL in PsAID-12 total scores at Wk 16 in patients who achieved PRO or clinical response

\begin{tabular}{|c|c|c|c|c|c|}
\hline \multicolumn{6}{|c|}{ Mean change from BL in PsAID-12 total score } \\
\hline $\begin{array}{l}\text { Response } \\
\text { Definition }\end{array}$ & $\begin{array}{l}\text { PBO } \\
n=66\end{array}$ & $\begin{array}{l}\text { Deucravacitinib } \\
6 \mathrm{mg} \text { QD } \\
\mathrm{n}=70\end{array}$ & $\begin{array}{l}P \text { value } \\
\text { vs PBO }\end{array}$ & $\begin{array}{l}\text { Deucravacitinib } \\
12 \mathrm{mg} \text { QD } \\
\mathrm{n}=67\end{array}$ & $\begin{array}{l}P \text { value } \\
\text { vs PBO }\end{array}$ \\
\hline \multicolumn{6}{|l|}{ PROs } \\
\hline $\begin{array}{l}\text { Patient global VAS } \\
(\leq-10.0)\end{array}$ & $-1.6(n=40)$ & $-2.8(n=54)$ & 0.0008 & $-2.9(n=48)$ & 0.0003 \\
\hline $\begin{array}{l}\text { Patient pain VAS } \\
(\leq-10.0)\end{array}$ & $-2.3(n=32)$ & $-3.4(n=44)$ & 0.004 & $-3.3(n=45)$ & 0.004 \\
\hline $\begin{array}{l}\text { HAQ-DI } \\
(\leq-0.35)\end{array}$ & $-2.8(n=10)$ & $-3.8(n=27)$ & 0.09 & $-3.8(n=27)$ & 0.11 \\
\hline $\begin{array}{l}\text { FACIT-Fatigue } \\
(\geq 4.0)\end{array}$ & $-2.4(n=27)$ & $-3.3(n=36)$ & 0.02 & $-3.6(n=41)$ & 0.002 \\
\hline $\begin{array}{l}\text { SF-36 PCS } \\
(\geq 2.5)\end{array}$ & $-1.7(n=35)$ & $-2.7(n=44)$ & 0.02 & $-3.1(n=43)$ & 0.001 \\
\hline $\begin{array}{l}\text { SF-36 MCS } \\
(\geq 2.5) \\
\text { Clinician } \\
\text { assessments }\end{array}$ & $-2.1(n=21)$ & $-3.5(n=33)$ & 0.005 & $-3.8(n=31)$ & 0.0009 \\
\hline $\begin{array}{l}\text { PASDAS } \\
(\leq 3.2)\end{array}$ & $-3.1(n=6)$ & $-4.2(n=14)$ & 0.004 & $-4.5(n=15)$ & 0.0006 \\
\hline $\begin{array}{l}\text { PASI } 75 \\
\text { ( } \geq 75 \% \\
\text { improvement } \\
\text { from BL) }\end{array}$ & $-2.4(n=11)$ & $-3.7(n=25)$ & 0.05 & $-3.9(n=31)$ & 0.02 \\
\hline
\end{tabular}

PsAID-9 results were generally consistent with PSAID-12 (data not shown). Response definitions based on published literature.Higher FACIT-Fatigue scores indicate less fatigue.Higher SF-36 PCS and SF-36 MCS scores indicate less disability.BL, baseline: FACIT, Functional Assessment of Chronic Illness Therapy; HAQ-DI, Health Assessment Questionnaire-Disability Index; MCS, Mental Component Summary; NA, not applicable; PASDAS, Psoriatic Arthritis Disease Activity Score; PASI, Psoriasis Area and Severity Index; PCS, Physical Component Summary; PRO, patient-reported outcome; QD, once daily; SF-36, 36-item Short Form Health Survey; VAS, visual analog scale.

Acknowledgements: This study was sponsored by Bristol Myers Squibb. Professional medical writing assistance was provided by Peloton Advantage, LLC, an OPEN Health company, and funded by Bristol Myers Squibb. 
Disclosure of Interests: Laure Gossec Consultant of: AbbVie, Amgen, Boehringer Ingelheim, Bristol-Myers Squibb, Celgene, Eli Lilly, Gilead, Janssen, Novartis, Pfizer, and UCB, Grant/research support from: Amgen, Galapagos, Janssen, Lilly, Pfizer, Sandoz, Sanofi, Laura C Coates Speakers bureau: AbbVie, Amgen, Biogen, Celgene, Gilead, Eli Lilly, Janssen, Medac, Novartis, Pfizer, and UCB, Consultant of: AbbVie, Amgen, Boehringer Ingelheim, Bristol-Myers Squibb, Celgene, Eli Lilly, Gilead, Janssen, Novartis, Pfizer, and UCB, Grant/research support from: AbbVie, Amgen, Celgene, Eli Lilly, Pfizer, and Novartis, Alexis Ogdie Consultant of: Abbvie, Amgen, BMS, Celgene, Corrona, Gilead, Janssen, Lilly, Novartis, Pfizer, UCB; Grants: Pfizer to Penn, Novartis to Penn, Amgen to Forward/NDB; Royalties: Novartis to husband, Philip J Mease Consultant of: AbbVie, Amgen, Boehringer Ingelheim, Bristol Myers Squibb, Eli Lilly, Galapagos, Gilead, GlaxoSmithKline, Janssen, Novartis, Pfizer, SUN Pharma, UCB, Grant/research support from: AbbVie, Amgen, Boehringer Ingelheim, Bristol Myers Squibb, Eli Lilly, Galapagos, Gilead, GlaxoSmithKline, Janssen, Novartis, Pfizer, SUN Pharma, UCB, Thomas Lehman Shareholder of: Bristol Myers Squibb, Employee of: Bristol Myers Squibb, Miroslawa Nowak Shareholder of: Bristol Myers Squibb, Employee of: Bristol Myers Squibb, Lan Wei Shareholder of: Bristol Myers Squibb, Employee of: Bristol Myers Squibb, June Ye Shareholder of: Bristol Myers Squibb, Employee of: Bristol Myers Squibb, Jiyoon Choi Shareholder of: Bristol Myers Squibb, Employee of: Bristol Myers Squibb, Joe Zhuo Shareholder of: Bristol Myers Squibb, Employee of: Bristol Myers Squibb, Brandon Becker Shareholder of: Bristol Myers Squibb, Employee of: Bristol Myers Squibb.

DOI: 10.1136/annrheumdis-2021-eular.2709

\section{AB0561 DISEASE DURATION AND HLA-B27 POSITIVITY ALTER LONGTERM RETENTION RATE OF CERTOLIZUMAB PEGOL IN PATIENTS WITH PSORIATIC ARTHRITIS}

S. S. Koca ${ }^{1}$, Y. Pehlivan ${ }^{2}$, S. Akar ${ }^{3}$, S. Şenel ${ }^{4}$, H. Karadeniz ${ }^{5}$, O. Sosyal ${ }^{6}$, A. Yazici ${ }^{7}$, S. Yılmaz ${ }^{8}$, R. Piskin Sagir ${ }^{1}$, N. Inanc ${ }^{9}$, A. Karatas ${ }^{1}$, G. Yildirim Cetin $^{10}$, F. Onen ${ }^{11}$ on behalf of TURKBIO Study Group. ${ }^{1}$ Firat University School of Medicine, Department of Rheumatology, Elazig, Turkey; ${ }^{2}$ Uludağ University, School of Medicine, Department of Rheumatology, Bursa, Turkey; ${ }^{3}$ Katip Çelebi University, School of Medicine, Department of Rheumatology, Izmir, Turkey; ${ }^{4}$ Erciyes University School of Medicine, Department of Rheumatology, Kayseri, Turkey; ${ }^{5}$ Gazi University School of Medicine, Department of Rheumatology, Ankara, Turkey; ${ }^{6}$ Celal Bayar University School of Medicine, Department of Rheumatology, Manisa, Turkey; ${ }^{7}$ Kocaeli University School of MEdicine, Department of Rheumatology, Kocaeli, Turkey; ${ }^{8}$ Selcuk University School of Medicine, Department of Rheumatology, Konya, Turkey; ${ }^{9}$ Marmara University School of Medicine, Department of Rheumatology, Istanbul, Turkey; ${ }^{10}$ Kahramanmaraş Sutçu Imam University School of Medicine, Department of Rheumatology, Kahramanmaras, Turkey; ${ }^{11} 9$ Eylul University School of Medicine, Department of Rheumatology, Izmir, Turkey

Background: Several factors such as effectiveness, safety and compliance affect the drug survival in chronic disorders. Physicians take care of longterm retention rate and responses for discontinuation of candidate drug. Identification of predictors of clinical response to certolizumab-pegol (CZP) may aid the decision-making process for treating patients psoriatic arthritis (PsA).

Objectives: The purpose of this study to assess the drug survival of certolizumab pegol (CZP) in patients with PsA and to identify the predictors and reasons for discontinuation.

Methods: Data on patient characteristics, demographics, diagnosis, disease duration, treatment and outcomes have been collected since 2011 in Turkish Biologic (TURKBIO) Registry. By the end of December 2020, 68 PsA patients received CZP and were included. Kaplan Meier plot was used for drug survival analysis. Cox regression analysis was performed to evaluate the predictors associated with drug survival.

Results: During the median 47 months follow-up, 17 patients discontinued the CZP treatment. The reasons for discontinuation were ineffectivity (35.3\%), adverse event $(17.6 \%)$ and pregnancy $(5.9 \%)$. The baseline characteristics of the patients who continued and discontinued CZP were shown in the Table 1. Patients who discontinued CZP had higher mean age and disease duration. HLA-B27 positive patients had lower retention rate while bDMARD naive patients had higher retention rate. At the month 36 , retention rate of CZP was $61.6 \%$ on patients with PsA (Figure 1).

Conclusion: Real life experience from this nationwide TURKBIO registry show that the retention rate of CZP in PSA are lower in older patients and with longer disease duration. Moreover, bDMARD naive patients have higher retention rate.

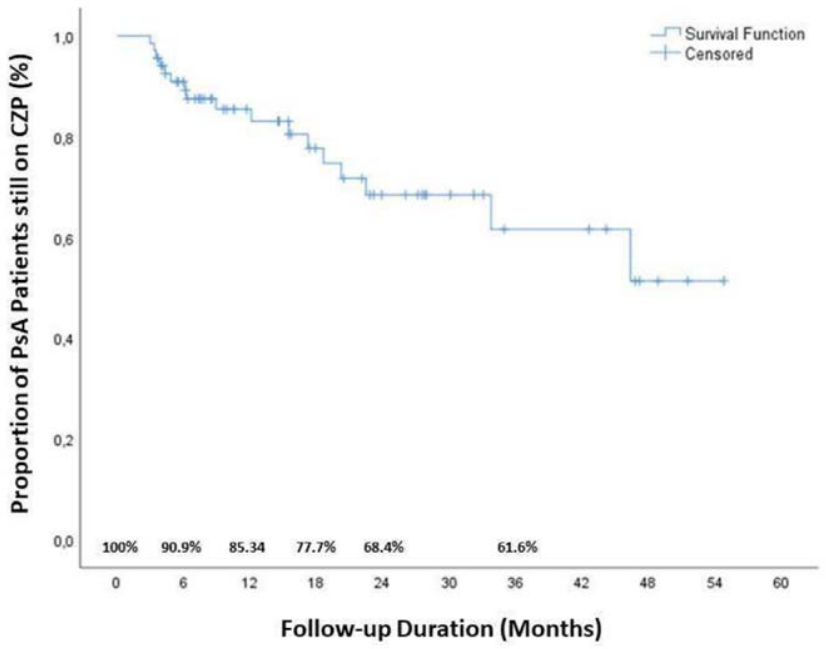

Figure 1. Drug survival of CZP in patients with PsA

Table 1. Baseline characteristics of PsA patients who continue and discontinue CZP

\begin{tabular}{|c|c|c|c|c|}
\hline & $\begin{array}{l}\text { All Patients } \\
(n=68)\end{array}$ & $\begin{array}{l}\text { Continue to CZP } \\
(n=51)\end{array}$ & $\begin{array}{l}\text { Discontinue to } \\
\text { CZP }(n=17)\end{array}$ & p \\
\hline Females, n (\%) & $52(76,5)$ & $37(72,5)$ & $15(88,2)$ & 0,322 \\
\hline Age, years & $44(36-57)$ & $40(35-53)$ & $51(42-60)$ & 0,012 \\
\hline $\begin{array}{l}\text { Disease Duration, } \\
\text { years }\end{array}$ & $9(5-13)$ & $8(5-12)$ & $14(10,5-17)$ & 0,002 \\
\hline $\begin{array}{l}\text { Symptom duration, } \\
\text { years }\end{array}$ & $11(7-16)$ & $10(7-15)$ & $15,5(11,5-20)$ & 0,014 \\
\hline $\begin{array}{l}\text { Order of CZP in } \\
\text { bDMARDs }\end{array}$ & $1(1-2)$ & $1(1-2)$ & $2(1-2)$ & 0,062 \\
\hline HLA-B27, n (\%) & $9(28,1)$ & $3(14,3)$ & $6(54,5)$ & 0,035 \\
\hline $\mathrm{ESR}, \mathrm{mm} / \mathrm{h}$ & $23,5(11-37)$ & $23(9-35)$ & $24(17-52)$ & 0,246 \\
\hline $\begin{array}{l}\text { Swollen Joint } \\
\text { Counts, } n\end{array}$ & $0(0-2)$ & $0(0-2)$ & $1(0-2)$ & 0,480 \\
\hline $\begin{array}{l}\text { Tender Joint } \\
\text { Counts, } \mathbf{n}\end{array}$ & $2(0-4)$ & $1(0-4)$ & $2(1-5)$ & 0,143 \\
\hline CRP, mg/dl & $4(3-13,65)$ & $3,14(3-13)$ & $5(3-19)$ & 0,107 \\
\hline HAQ & $0,63(0,25-1)$ & $0,63(0,25-1)$ & $0,75(0,63-0,94)$ & 0,097 \\
\hline VAS-Physicians & $20(12-31,5)$ & $20(12-26)$ & $30(15-50)$ & 0,074 \\
\hline VAS-Patient Global & $50(27-70)$ & $50(20-70)$ & $61,5(46,5-70)$ & 0,342 \\
\hline VAS-Patient Pain & $53(28-75)$ & $50(20-75)$ & $69(49,5-75)$ & 0,122 \\
\hline DAS-28-CRP & $3,35(2,2-3,9)$ & $2,85(2-3,8)$ & $3,6(2,9-4,4)$ & 0,086 \\
\hline BASFI & $15(8-27)$ & $14(5-26)$ & $23,5(12-30,5)$ & 0,133 \\
\hline BASDAI & $28(16-40)$ & $27,5(14-36)$ & $39(22,5-41,5)$ & 0,060 \\
\hline $\begin{array}{l}\text { ASDAS } \\
\text { DAPSA-28 }\end{array}$ & $\begin{array}{l}2,7(1,9-3,2) \\
15,35(7,2-21,9)\end{array}$ & $\begin{array}{l}2,6(1,9-3,1) \\
14,9(6,1-21,17)\end{array}$ & $\begin{array}{l}3(2,35-3,4) \\
18,9(14,15-29,3)\end{array}$ & $\begin{array}{l}0,122 \\
0,108\end{array}$ \\
\hline
\end{tabular}

Disclosure of Interests: None declared

DOI: 10.1136/annrheumdis-2021-eular.2832

\section{AB0562 POTENTIAL BIOMARKERS OF PERSONALIZED TREATMENT BASED ON CARDIOVASCULAR- RELATED COMORBIDITIES IN PSORIATIC ARTHRITIS}

I. Arias de la Rosa ${ }^{1}$, M. D. López Montilla², C. Román-Rodriguez², I. Gómez García $^{2}$, M. J. Pérez Galán ${ }^{3}$, I. Añón Oñate ${ }^{3}$, M. D. C. Abalos-Aguilera², C. Perez-Sanchez ${ }^{2}$, D. Ruiz' ${ }^{2}$ A. M. Patiño-Trives ${ }^{2}$, M. Luque-Tévar ${ }^{2}$, M. L. Ladehesa Pineda², C. López-Medina², C. Lopez-Pedrera², A. Escudero Contreras ${ }^{2}$, E. Collantes Estevez ${ }^{2}$, N. Barbarroja Puerto ${ }^{1} .{ }^{1}$ Maimonides Institute for Research in Biomedicine of Cordoba (IMIBIC)/Reina Sofia Hospital/University of Cordoba, Medicine Department, Cordoba, Spain; ${ }^{2}$ Maimonides Institute for Research in Biomedicine of Cordoba (IMIBIC)/ Reina Sofia Hospital/University of Cordoba, Rheumatology Department, Cordoba, Spain; ${ }^{3}$ University Hospital of Jaen, Rheumatology Department, Jaen, Spain

Background: Psoriatic Arthritis ( $\mathrm{PsA}$ ) displays increased traditional cardiovascular (CV) risk factors, such as insulin resistance (IR), metabolic syndrome or obesity. Thus, it is an urgent need to treat and manage these 